\title{
The Effect of Both UV\Ozone and Chitosan on Natural Fabrics
}

\author{
Eman Mohamed Osman (Corresponding author) \\ National Institute for Standards, Chemistry Metrology Division \\ Textile Metrology Lab., Tersa st. El Haram, Giza, Egypt \\ P.O. Box: 136 Giza, Code: 12211
}

Tel: 202-3740-1116_E-mail: eman_osman21@yahoo.com

Monira Nesim Michael

Head of the Electricity Division

National Institute for Standards, Chemistry Metrology Division

Textile Metrology Lab., Tersa st. El Haram, Giza, Egypt

Hoda Gohar

National Institute for Standards, Chemistry Metrology Division

Textile Metrology Lab., Tersa st. El Haram, Giza, Egypt

\begin{abstract}
This work has focused on developing eco-friendly treatments for modifying the fabric surface. Thus; we studied in details the effect of individual and combined uvlozone and chitosan on wool and silk fabric samples. All the treated samples are characterized and evaluated by: i) Fourier transform infrared spectra with attenuated total reflection analysis (FTIR-ATR), ii) Performance properties, iii) Mechanical measurements, and iv) Dyeing characteristics using two different dye classes namely, reactive dye (C.I. Reactive Orange 69) and direct dye (C.I Direct Yellow 11) applied on both wool and silk samples modified with the above mentioned three techniques.
\end{abstract}

Keywords: Uvlozone, Chitosan, Young's Modulus, FTIR-ATR, Performance, Mechanical, Dyeing

\section{Introduction}

In recent years a great attention has been evoted to biopolymers because of their biocompatibility and biological functions and consequently, potential application in the biomedical and pharmaceutical fields. Chitosan is an examples of these biopolymers having B- 1,4 linked glucose amine residues, the second most abundant polysaccharide found on earth next to cellulose. Chitosan has a great potential for a wide range of uses due to its biodegradability, biocompatibility, antimicrobial activity, non-toxicity and ability to improve wound healing (Eagle, 2003).

In the textile industry, chitosan is used as print- paste thickener and is also used to improve the antimicrobial property of textile. Textile fibers that having poor affinity for dyes can be blended or surface coated with chitosan which makes them more receptive to dyeing with many dyes (Bahmani et al, 2006). Chitosan can also be used in the dye bath to improve the dyeability of textiles. This might be due to the improved electrostatic attraction between the protonated amino group in chitosan and the anionic dye leading to extremely high affinity for many classes of dyes (Wyeth et al, 2004).

The surface of the fiber has an important effect on overall processing properties of the fabrics. For wool fabrics, modification of the outer epicuticle and exocuticle imparts beneficial improvement to wool dyeability, printability, wettability .... The outermost surface of the wool fiber is thought to have a covalently bound lipid layer, which is responsible for the hydrophobic nature of the epicuticle. The main component of the surface lipid is a $\mathrm{C}_{21}$ - fatty acids which are thought to be bound to the epicuticle mainly by thioester linkages to cystine residues. Notably, aqueous chlorination treatments have been used to modify the wool surface (Michael \& El-Zaher, 2004). 
Exposure of silk to sunlight produces an obvious photo- yellowing followed by photo- tendering. Silk yellowing is due to the photo- oxidation of tyrosine and tryptophane residues, resulting in the formation of yellow chromophores. Tyrosine is considered the most important source of silk yellowing due to its greater abundance. Silk photo- tendering is caused by the breakage of peptide bonds occurring initially at the weaker C-N bond (Phattanarudee \&Kiatkanjornwong, 2008).

Recently, with the present national and international awareness of environment, ecology and environmental legislation, this work is focused on using individual and combined uvlozone and chitosan treatments both can be described as dry and biopolymer treatment respectively to achieve the same processing benefits as aqueous processing.

\section{Experimental Work}

\subsection{Materials}

\subsubsection{Fabrics}

- Silk fabric, weight is $69.83 \mathrm{~g} / \mathrm{m} 2$ and thickness is $0.21 \mathrm{~mm}$, it is supplied by El-Khateeb Factory, Akhmeem, Egypt, purified in laboratory by scouring with a solution containing $5 \mathrm{~g} / \mathrm{l}$ of detergent using liquor ratio $1: 50$ at temperature $40^{\circ} \mathrm{C}$ for 15 minutes (Osman, 2001).

- Wool fabric, weight is $176.71 \mathrm{~g} / \mathrm{m} 2$ and thickness is $0.528 \mathrm{~mm}$, it is supplied by Golden Tex Company, Egypt, and purified in laboratory by scouring with a solution containing $2 \mathrm{~g} / \mathrm{l}$ of non- ionic detergent using liquor ratio $1: 50$ at temperature $60^{\circ} \mathrm{C}$ for 15 minutes.

Finally, all the samples are thoroughly washed with tap water and dried at ambient conditions.

\subsubsection{Chemicals}

\section{- Chitosan}

Highly viscous chitosan (poly (1,4)- 2- amino- 2 deoxy- B- D- glucose) (Gohar, 2006), supplied by Fulka Chemie GmbH- 9471 Buchs, Sigma- Aldrich.

- Dyes

Direct dye: Drimarin yellow (C.I. Direct Yellow 11) and

Reactive dye: Difloro-chloro prymidine (C.I. Reactive Orange 69).

These two dyes are supplied by Clariant Company.

\section{Modification Methods}

\subsection{UVlOzone Treatment (Treatment I)}

The samples under test - either wool or silk- in the form of strips are firstly exposed to UV source in a medium of ozone for 20 minute. A high intensity, low pressure mercury lamp without outer envelope- LRF- 02971, 200 watt, 220 volts, made in Poland- is placed in a cubic box with side length $60 \mathrm{~cm}$, and the samples were put around the source at distance $20 \mathrm{~cm}$. Molecular oxygen is subjected to the $184.9 \mathrm{~nm}$ radiation and when ozone is irradiated at $253.7 \mathrm{~nm}$, the radiation is absorbed by most hydrocarbons and also by ozone (Michael \&El-zaher, 2004). The products of this excitation react with atomic oxygen to form simpler, volatile molecules, which desorbed from the surfaces. Therefore, when both wavelengths are present atomic oxygen is continuously generated and ozone is continually formed and then destroyed (Ibrahim, 2003). This is confirmed by measuring the produced $\mathrm{O}_{3}$, using $49 \mathrm{c}_{3}$ Analyzer Thermo Environmental Inst. Inc. USA.

\subsection{Chitosan Treatment (Treatment II)}

Different concentrations of chitosan $(0.5 \%, 1 \%, 1.5 \%$, and $2 \%)$ are freshly prepared by gradual dissolution a known weight of the powder in acidified water $(1 \%$ acetic acid) at room temperature. Trintol $(1 \mathrm{~g} / \mathrm{l})$ is added to the treatment bath just before padding. The samples under test are separately padded and then dried at $80^{\circ} \mathrm{C}$ for 5 minutes followed by thermo-fixation at $140^{\circ} \mathrm{C}$ for 3 minutes, finally washed with warm water (Eagle, 2003).

\subsection{Combined UV $\backslash$ Ozone and Chitosan (Treatment III)}

Another treatment is carried out using combined uvlozone and chitosan. Thus, wool and silk samples firstly exposed to UV source for 20 minutes under the above mentioned conditions (treatment I) followed by treatment with different chitosan concentrations as mentioned above (treatment II). 


\section{Testing and Analysis}

\subsection{Fourier Transform Infra Red Spectroscopy with Attenuation Total Reflection (FTIR-ATR)}

FTIR-ATR spectra of the above mentioned samples were recorded by means of Nicolet 380 Spectrometer using a zinc selenid crystal, in the wavelength range $650-4000 \mathrm{~cm}^{-1}$. To ensure reproducible contact between the crystal face and the fabric, a pressure of about $18 \mathrm{Kpa}$ (Barbara, 2005) is applied to the crystal holder. The FTIR absorbance frequencies for the treated samples are recorded with an average of 128 scans using a resolution of 4 $\mathrm{cm}^{-1}$.

\subsection{Mechanical Measurements}

Tensile strength and percentage elongation at break for all the samples under test were measured and evaluated using Shimadzu Universal Tester of type S-500 Japan. The measurements are carried out according to ASTMStandard Method 2000, D 3822-96.

Young's modulus (Y-values) of the measured samples which is inversely proportional to elasticity can be obtained from the ratio between tensile strength and elongation at break by applying the following equation (Keony, 1993).

Young's modulus $=\frac{\text { Force applied }}{\text { Unit area }} x \frac{\text { Initial length }}{\text { Increase In length }}$

\subsection{Wetting time}

It is time of complete immersion of a sample $(5 \mathrm{~cm} \times 5 \mathrm{~cm})$ dropped flat onto the surface of distilled water from a height of about $3 \mathrm{~cm}$ (AATCC , 79-1995). The wetting time is determined for all the above mentioned samples under test.

\subsection{Yellowness Index Determination:}

The yellowness index for all the different examined samples are measured and evaluated according to ASTM D 1925 using Color Eye 3100 Spectrophotometer SDL, England. The mean value of three measurements is recorded for each sample.

\section{Dyeing Testing and Analysis}

\subsection{Dyeing Method}

All the treated samples under test are separately dyed by each of the above mentioned dyes in a laboratory dyeing apparatus using the conventional exhaustion dyeing method without any addition of chemicals to the dyeing bath, where a fixed dye concentration of $2 \mathrm{~g} / \mathrm{l}$ is used (Eagle, 2003). All dyeings are carried out at temperature $80^{\circ} \mathrm{C}$ for 60 minutes with a liquor ratio of 1:50. The dyed samples are thoroughly washed and finally dried at ambient conditions.

\subsection{Color Strength $(K \backslash S)$ Determination}

The color strength $(\mathrm{K} \backslash \mathrm{S})$ values of the different examined samples are measured at the wavelength characteristic to each color (Christie et al, 2000). The measurements are carried out using Color Eye 3100 Spectrophotometer SDL, England.

\subsection{Light Exposure, Light Fastness Evaluation and Color Difference ( $(\Delta E)$}

The different examined dyed samples are exposed to artificial daylight using Xenon Tester (weathering) (AATCC, 169-RA 64,1995 ) at temperature $25 \pm 2{ }^{\circ} \mathrm{C}$ and relative humidity $65 \pm 5 \%$ alongside with a Standard Blue Scale. The fastness grades are assessed visually according to ASTM standard method (ASTM, G23, 1990) and the results are evaluated more precise from color difference measurements $(\Delta \mathrm{E})$ (Christie et al, 2000).

\section{Results and Discussion}

Wool polymer contains some important chemical groups that able to form inter-polymer forces of attraction. These groups are: the polar peptide groups (i.e. -CO-NH-) and the carbonyl groups (-CO-), which will form hydrogen bonds with the slightly positively charged hydrogen of the imino groups (-NH-) of another peptide groups. Besides, some wool polymers have carboxylate groups (-COO-), and amino groups $\left(-\mathrm{NH}_{3}{ }^{+}\right)$as side groups, between these two groups salt linkages or ionic bonds will form. Also, cystine linkages, the sulphurcontaining amino acid (i.e. disulphide bonds) are very strong since they form covalent bonds. Finally, the existence of the above mentioned inter-polymer forces tends to make the van der Waals' forces rather significant (Tamada, 2004),

Silk polymer is composed of sixteen different amino acids compared with the twenty amino acids of wool polymer. Three of these sixteen amino acids namely, alanine, glycine and serine, make up about four-fifth of the 
silk polymers ' composition. Also, silk polymers are not composed of any amino acid containing sulphur. So, silk may be considered to have the same composition as that of wool except that the silk polymer system hasn't disulphide bonds. The important chemical groupings of the silk polymer are the peptide groups which give rise to hydrogen bonds, and the carboxyl and amine groups which give rise to the salt linkages(Jun \& Chen, 2006). Table (1) shows the percentage ratio of some amino acids present in both wool and silk fabrics. The amino acids found in silk fabric are joined by sericin gum. Glycin, serine and alanine are found in the crystalline portion, where the bulky side chains are found in the amorphous region.

\subsection{Fourier Transform Infrared Spectra (FTIR-ATR) Analysis}

FTIR-ATR (Barbara, 2005) has been employed to study the effect of the three treatment techniques on the behavior of the different function groups as well as the different amino acids present in both wool and silk fabric samples , the results are shown in tables $(2 \& 3)$ respectively.

The absorption band at $3566 \mathrm{~cm}^{-1}$ assigned to O-H asymmetric stretching in wool samples, it is a sharp and strong band, and the change in its intensity is directly proportional to the dipole-dipole moment of the molecule (Phattanarudee\& Kiatkanjornwong, 2008).

The absorption band at $\approx 3275 \mathrm{~cm}^{-1}$ assigned to N-H stretching of the serine amino acid in both wool and silk samples, and its presence ratio is $8.97 \%$ and $12.49 \%$ respectively (Yuen et al, 2007).

The band at $\approx 2920 \mathrm{~cm}^{-1}$ assigned to $\mathrm{C}-\mathrm{H}$ stretching is observed at the spectra of both two fabrics wool and silk.

The signal at $1645 \mathrm{~cm}^{-1}$ assigned to $\mathrm{C}=\mathrm{O}$ stretching of aspartic acid is observed only in wool spectra, its presence ratio is $\approx 6.19 \%$

The band at $1610 \mathrm{~cm}^{-1}$ assigned to $\mathrm{N}-\mathrm{H}$ bending of lysine amino acid present in both spectra of wool (3.34\%) and silk $(0.66 \%)$ samples.

The band $\approx 1515 \mathrm{~cm}^{-1}$ assigned to $\mathrm{C}=\mathrm{O}$ asymmetric of glutamic acid, is found in both spectra of wool (13.11\%) and silk (2.08\%).

The signal at $v=1443 \mathrm{~cm}^{-1}$ assigned to $\mathrm{C}-\mathrm{C}$ stretching in ring of tyrosine, is found only in silk spectrum, its presence ratio is $\approx 10.63 \%$.

The band $\approx 1231 \mathrm{~cm}^{-1}$ assigned to $\mathrm{C}-\mathrm{N}$ stretching in only found in silk samples spectrum.

The signal at $v=1070 \mathrm{~cm}^{-1}$ assigned to cystine oxides (monoxide and dioxide) is only found in wool spectrum.

In general, there is an increase in the peak intensity values of all the characteristic bands for both fabric samples under test after their treatment with uvlozone for 20 minutes. Also, when the blank samples are treated with $0.5 \%$ chitosan, the peak intensity of all the characteristic bands for both fabrics increases followed by a gradual increase in the intensity values with increasing chitosan concentration (from $0.5 \%$ to $2 \%$ ) except the band at $3566 \mathrm{~cm}^{-1}$ of O-H asymmetric stretching and the band at $1070 \mathrm{~cm}^{-1}$ of cystine for wool samples and band at 1619 $\mathrm{cm}^{-1}$ of N-H bending of lysine amino acid for silk samples. The decrease in cystine oxides band intensity may be due to the conversion of cystine oxide to cystine amino acid (Phattanarudee\& Kiatkanjornwong, 2008).

On treating blank samples with uvlozone followed by different chitosan concentrations, most of the function groups belonging to wool samples show increase in the intensity values with increasing chitosan concentrations, while the function groups characteristic to silk samples depict decrease in the intensity values with increasing chitosan concentration

\subsection{Effect of the Different Treatment Methods on the Performance properties of Wool and Silk samples}

\subsubsection{Whiteness (W) and Yellowness (Y) Indices}

The change in yellowness and whiteness indices can be considered as a sensitive indication of surface modification for the natural fabrics under test during the different treatments. Table (4) shows the effect of the three different treatment techniques on yellowness and whiteness indices.

For treatment I, there is enormous increase in yellowness values of silk samples compared to that obtained in wool which shows a slight increase in yellowing and the reverse of these results holds true for whiteness trend. These can be attributed to: i) The presence of disulphide covalent bonds in wool polymer and its increasing after treatment I as mentioned in table (2) resisting the yellowing, ii) presence and higher content $\%$ of the amino acids tyrosine and serine respectively -which are the most important source of yellowing and it's increase with uvlozone exposure (tables $2 \& 3$ ), whereas the increment in silk is higher than that in wool. Besides, the amino acids may be photo-oxidized via exposure to uvlozone resulting in the formation of yellow chromophores (Jun \& Chen, 2006). 
For treatment II, the yellowness values of silk samples were higher than that of wool samples and tend to increase with increasing chitosan concentrations while for wool a decrease in yellowness is observed. The observed decrease in yellowness values of wool samples can be attributed to its structure characteristics where the type and the content of the different amino acids increase with increasing chitosan concentration as indicated from FTIR (table 2). Such chitosan layer has been reported to adhere tightly to wool through thermosetting process and ionic interaction between the carboxyl groups in wool and the free amino groups in chitosan, besides hydrogen bonding between hydroxyl groups of chitosan and the amino groups of wool (Michael \& El-Zaher, 2004)

For treatment III, the yellowness values of silk samples show a significant increase at the lowest chitosan concentrations followed by decrease with increasing chitosan concentration. While for wool samples, there is a very slight gradual increase in yellowness values with increasing chitosan concentrations. The observed yellowness increase at lower chitosan concentrations can be attributed to the predominant effect of uvlozone as mentioned in treatment I. For treated silk samples, on increasing chitosan concentrations, both the coating layer thickness and ionic interaction increase leading to a decrease in the yellowness of the surface. For wool samples, the photo-yellowing on the surface is due to the increase in the intensity of amino acids with uvlozone that responsible for producing colored products is predominate over the coating layer formed by chitosan. In general, the natural coloration of chitosan that appears yellowish to some extent increase yellowness with increasing the thickness of the coating layer, especially in case of treatment with uvlozone (Bahamani et al, 2006; Yuen et al, 2007)

In short, the results indicate that, the ranking order of the yellowness index follow the order: For wool: treatment III (at the highest chitosan concentration) $>$ treatment I > treatment II (at the highest chitosan concentration)

For silk: treatment II (at the highest chitosan concentration $>$ treatment I $>$ treatment III (at the highest chitosan concentration)

\subsubsection{Wettability}

It is well known that wool is more hydrophobic than silk, this agrees with the obtained results) where the wetting time of blank wool samples is much higher than that of silk in (table 5). On exposing wool and silk samples to uvlozone for 20 minutes, the wetting time of both fabrics are decreased by about $56 \%$ and $50 \%$ respectively. This can be interpreted on the results obtained from FTIR spectra (tables $2 \& 3$ ) where there is an increase in the intensity of the different function groups and amino acids that responsible for increasing the surface polarity of samples under test, i.e. become more hydrophilic leading to improving the wettability (Gohar, 2006) consequently decreasing the wetting time.

For both treatments II\& III, there is an enormous decrease in the wetting time with increasing chitosan concentrations for the two fabrics under test, i.e. the wettability of wool is greatly improved compared to silk, especially at the highest chitosan concentrations. This result can be explained on the light of the increment intensity of different function groups and amino acids for both fabrics (tables $2 \& 3$ ), taking into consideration that the increment in wool is much higher than that of silk. Moreover, the characteristic nature of silk yarns which are more compacted than wool, so when the yarns are coated with viscous chitosan it can pack and glue yarn together reducing the voids of inter-fiber spaces. As a result, the solution can not further penetrate into the yarns because the decreased inter fiber spaces can not accommodate a large amount of water remaining on the surface (Phattanarudee \& Kiatkanjornwong, 2008), each relative to its blank sample.

Generally, the improvement of the wettability (i.e. less wetting time) follows the order:

For both wool and silk: treatment III (at the highest chitosan concentration) > treatment II (at the highest chitosan concentration) $>$ treatment I.

\subsection{Mechanical Properties of the Treated Wool and Silk Samples}

The change in the mechanical properties of the treated wool and silk samples using the three different treatment techniques reflect not only the changes in the chemical structure of the polymer system but also its morphology (Wyeth et al, 2004)

The data in table (6) clarify the effect of the different techniques on the mechanical properties of both wool and silk samples under test. For treatment I, there is a decrease in \%elongation for both fabrics under test and a slight change is observed in case of tensile strength and young's modulus (that is inversely related to elasticity.

For treatment II, there is no detectable change in tensile strength values observed with increasing chitosan concentrations in case of wool samples; while in case of silk samples an increase is observed at higher chitosan 
concentrations. Regarding to the \%elongation, a gradual decrease is observed for both fabrics under test. The observed change in young's modulus shows a gradual increase in wool and a gradual decrease in silk samples.

For treatment III, there is no detectable change is observed in the tensile strength values for wool samples while for silk samples increase with increasing chitosan concentrations. Moreover, \%elongation and young's modulus of wool samples increase and that of silk samples decrease with chitosan concentrations compared to the blank ones.

Many scientists have correlated the resulting alteration in mechanical properties of the treated protein samples with chemical changes in keratin structure and amino groups. The main reason for losing fiber strength was assumed to be the cleavage of the cystine bridges or of the main chain bonds between carbon atom and amide $\mathrm{N}$-atom of the wool proteins (Wilson et al, 2000)

On this basis, the change in the mechanical properties can be correlated with the change in chemical groups and amino acids with the treatment techniques as detected from FTIR-ATR spectra (tables 1\&2). Where the observed change in the mechanical properties can be related to the change in both amino acids and carboxyl groups content, these are the basis for salt-links between adjacent keratin chains.

In general, it is found that, the mechanical properties of wool samples are improved while for silk, the tensile strength is improved and both \%elongation and young's modulus are decreased.

\subsection{Effect of the Three Different Treating Techniques on the Dyeing Properties}

The dyeing properties of the treated dyed fabrics are examined throughout studying two main parameters; dyeability expressed as color strength (K\S) and fastness to light which is assessed visually using the Standard Blue Scale and evaluated instrumentally by measuring the color difference parameter $(\Delta \mathrm{E})$ to give more accurate and precise value for the actual amount of faded dye (Christie et al, 2000). On this basis, the dyeings are carried out using two different dye classes namely, reactive difluoro-chloro pyrimidine (C.I. Reactive Orange 69) and direct drimarin yellow (C.I. Direct Yellow 11).

Table (7) and figure (1) clarify the effect of the different treatment techniques on the dyeing properties of wool and silk samples using difloro-chloro prymidine (C.I. reactive orange 69) with general formula (Korchagin \& Matetsk, 1973):

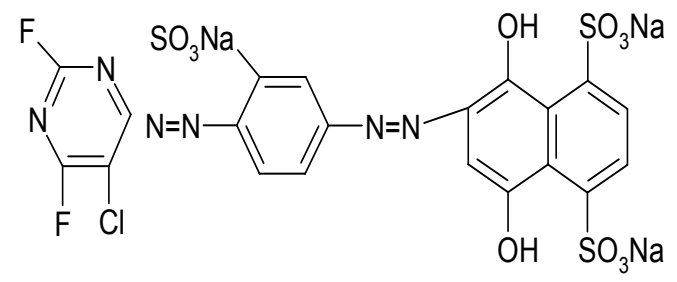

Difloro-chloro prymidine

Generally, the structure of this dye contains a large number of polar constituents $\left(-\mathrm{OH}^{-}, \mathrm{SO}_{3}{ }^{-}\right)$which are very active to react with the reactive side groups of the fabric samples through covalent bond formation and the chance of this reaction increases by increasing the active side groups on treated samples (Korchagin \& Matetsk, 1973).

It is clear from the results that, the dyeing properties of blank wool samples are higher than that of silk ones; this can be related to their natures. In wool keratin, there are a variety of functional groups with which reactive dyes may react. These groups include the amino $\left(-\mathrm{NH}_{2}\right)$, hydroxyl $(-\mathrm{OH})$, thiol $(-\mathrm{SH})$ and carboxyl $\left(\mathrm{COO}^{-}\right)$which can react with the dye forming hydrogen bonding and covalent bonds. While in silk, the link to the dye is carried out through (-NH) group (Tamada, 2004).

For treatment I, it is obvious that, there is an improvement in the dyeing properties for both fabrics as $(\mathrm{K} \backslash \mathrm{S})$ and (L.F.) values increase and $(\Delta \mathrm{E})$ decrease and the improvement in wool is greater than that in silk. This can be attributed to the effect of uvlozone exposure, where the intensity of the above mentioned function groups increase (tables $2 \& 3$ ).

Treatment II shows a gradual increase in dyeability of both fabrics with increasing chitosan concentrations. Also, the increment in wool is greater than that in silk samples; this can be related to the increasing intensity of the amino groups with increasing chitosan concentrations. These groups have been reported to act as a built-in 
catalyst on the treated samples and to imparting a cationic surface which attracts the oppositely charged dye anions leading to enhancement the dyeability and the light fastness (Jocic et al, 2005)

It has been reported that dyeing properties depend mainly on the dye concentration and nitrogen content of chitosan pretreatment within the surface of the fabrics (Phattanarudee \& Kiatkanjornwong, 2008). This has been explained by interaction between the protonated amino groups of chitosan and anionic dyes via ionic interaction through an ion exchange process, and hence the color difference $(\Delta \mathrm{E})$ values decrease.

The greater improvement of wool dyeing properties with chitosan concentrations is related to (NH) group which is responsible for the basicity of wool. Although wool itself contain amino groups, further introduction of amino groups on the wool fabric surface as a result of modifications leading to induction of new dye site on the fibers, enhancing the absorption-ability of wool (Gohar, 2006), thus causing the wool fiber to become more hydrophilic and this increase the dye-uptake.

For treatment III, there is an increase in $(K \backslash S)$ values with increasing chitosan concentrations. The highest (K\S) values obtained after treatment III compared to treatments I\& II which can be related to either higher chitosan adsorption occurs on both samples pretreated with uvlozone or the treatment with uvlozone activate some functional groups followed by chitosan which activate another functional groups, the net result is increasing the number and intensity of the activated function groups. So, highest $(\mathrm{K} \backslash \mathrm{S})$ values are obtained alongside with (L.F) values.

Table (8) and figure (2) represent the dyeing properties data of wool and silk samples dyed with direct drimarin yellow (C.I. Direct Yellow 11) with the formula (Korchagin \& Matetsky, 1973):<smiles>Nc1c(N=Nc2ccc(-c3ccc(N=Nc4cc([N+](=O)[O-])c5ccccc5c4N)cc3)cc2)cc([N+](=O)[O-])c2ccccc12</smiles>

Drimarin yellow

Generally, direct dyes interact with wool according to the following:<smiles>[R]OC(=O)NSOS(=O)(=O)O[Na]</smiles>

From the chemical structure of this dye (Korchagin, \& Matetsky 1973), there is an amino group in Para position to the azo group; this makes the dye in a clear coplanar structure having long chain and this interns increase the chance for interaction with the fiber via hydrogen bond. Besides, promoting the formation of aggregated particles easily exhausted and diffused inside the fiber pores and since wool having higher porosity than silk so $\mathrm{K} \backslash \mathrm{S}$ values of blank wool samples are greater than that of silk as indicated from table (8).

For treatment I, it is found that, both color strength (K\S) and light fastness (L.F) increase with uv/ozone exposure for both fabrics and the color difference values $(\Delta \mathrm{E})$ decrease.

For both treatments II and III, the results show that the dyeability characteristics of wool (K\S and L.F) are higher than that of silk and tend to increase with increasing chitosan concentrations. This can be related to the nature of wool which has a variety of function groups $(\mathrm{OH}, \mathrm{NH}, \mathrm{SH}$ and $\mathrm{COO})$ that can react with the dye forming hydrogen and covalent bond while silk can react only through the NH groups (Tamada, 2004)

In short, the results clarify that the improvement in the dyeing properties (KIS and L.F) of both reactive and direct dyes applied on both fabrics wool and silk take the order: treatment III (at the highest chitosan concentration) $>$ treatment II (at the highest chitosan concentration) $>$ treatment I. While the corresponding color difference values $(\Delta \mathrm{E})$ follow the reverse trend.

\section{Conclusion}

This work studies in detail the effect of three different treatment techniques individual and combined uvlozone and different chitosan concentrations on wool and silk protein fabrics. Treatment I: exposure to uvlozone for 20 minutes, treatment II: different chitosan concentrations and treatment III: combined the above two techniques (I $\&$ II). The evaluation of these three techniques is carried out through studying FTIR-ATR spectra which indicate that there is an improvement in the different function groups characterizes each fabric and this give an indication 
for the improvement in the performance properties and dyeing characteristics. On this basis, the performance properties of the pretreated fabrics are studied that include whiteness and yellowness indices (W \& Y) and the wettability (sec.). The results of yellowness index indicate that, the yellowness values of treated silk samples are higher than that of wool and take the following order for both fabrics: treatment III (at the highest chitosan concentration) $>$ treatment II (at the highest chitosan concentration ) > treatment I

As it is known, wool is more hydrophobic than silk and the results of wettability show that, the wetting time of treated wool samples are greatly improved (i.e. become more hydrophilic) after each treatment. So, the improving in wettability of both fabrics takes the order: Treatment III (at the highest chitosan concentration) $>$ treatment II (at the highest chitosan concentration) > treatment I compared to the corresponding blank samples.

In regarding to the mechanical properties of the tested samples it is found that, the mechanical properties of wool are improved while for silk, only the tensile strength is improved where both \%elongation and young's modulus are not.

When studying the dyeing properties of the wool and silk samples dyed with either reactive or direct dye, it is found that, there is increase in KIS and L.F. values (i.e. improving the dyeability) of the treated samples for both dyes compared with the untreated dyed ones due to increasing the hydrophilicity of the treated fibers.

\section{References}

AATCC. (1995). Test Method 79.

AATCC. (1995). Xenon Lamp Exposure, 169- RA 64.

ASTM, G 23. (1990).

Bahmani, S.A., East, G.C., \& Holme, I. (2006). JSDC, 116, 94-99.

Barbara, H. (2005). Infrared Spectroscopy: Fundamentals and Application, John Wiley\& Sons, Ltd., Southern Gate, Chichester, England.

Christie, R.M., Mather, R.R., \& wardmum, R.H. (2000). The chemistry of Color Application, Blackwell Science, London.

Eagle, W.Y.G., (2003). The Effect of Chitosan and its Derivatives on the Dyeability of Silk, Ph.D. Thesis, Hong Kong Polytechnic University.

Gohar, H.H. (2006). Evaluation and Characterization of the Physicochemical Properties of Wool Fabric Exposed to UvlOzone and Treated with Natural Biopolymer, MSc. Thesis, Faculty of applied Arts, Helwan University, Egypt.

Ibrahim., S.F. (2003). Investigation into the Effect of UV\Ozone treatments on Physical Properties and Dyeing Kinetics of Some Polymeric Fabrics, Ph.D. Thesis, Faculty of science, Cairo university, Egypt.

Jocic, D., Vilchez, S., Topalovic, T., et al, (2005). Carbohydrate Polymers, 60, 51-59.

Jun, Z., \& Chen, G.Q., (2006). The study of the Structures of Silk Fibers Grafted with Hexaflurobutyl Methacrylate, International Forum of textile and Engineering for Doctoral candidates, China.

Keony, F.P. (1993). The Proceeding of the $16^{\text {th }}$ Roc. Polymer Symposium, vol. IX, 1, p. 373

Korchagin, F. M., \& Matetsky, A. (1973). Chemical Technology of Fibrous Materials, MIR publishers, Moscow.

Michael, M.N., \& El-Zaher, N.A. (2004). Egypt. J. Chem., 47, 1, 93-100.

Osman, E.M. (2001). Applying Natural Dyed on Natural Fabrics and Studying Their Diffusion Kinetics and Photo Fading Characteristics, Ph.D. Thesis, Faculty of science, Helwan University, Egypt

Phattanarudee, S. K., \& Kiatkanjornwong, S. (2008). Pretreatment of Silk Fabric Surface with Amino Compounds for Ink Jet Printing, Progress in Organic Coatings.

Tamada, Y. (2004). Sulfation of silk fibroin by Chlorosulfonic Acid and the Anticoagulant Activity, Biomaterials, 25, 3, 377-383.

Wilson, D., Valluzzi, D., \& Kaplan, D. (2000). Biophysical Journals, 78, 2690-2701.

Wyeth, p., Greiff, s., Kutzke. H. S., \& Riekel, C. (2004). Surveying Silk Fiber Degradation by Crystallinity Determination: a Study on the Tang-Dynasty Silk Treasure from Famen Temple, China. [Online] Available: http://eprints.soton.ac.uk/17245

Yuen, C.W.M., Ku, S.K.A., Kan, C.W., \& Choi, P.S.R. (2007). Coloration technology, 123, 267-270. 
Table 1. The percent ratio of amino acids in both wool and silk

\begin{tabular}{|c|c|c|}
\hline Amino acids & The content percent in wool & The content percent in silk \\
\hline Serine & 8.97 & 12.49 \\
\hline Lysine & 3.34 & 0.66 \\
\hline Glutamic & 13.11 & 2.08 \\
\hline Aspartic & 6.19 & ------- \\
\hline Tyrosine & ------- & 10.63 \\
\hline cystine & 11.3 & -------- \\
\hline
\end{tabular}

Table 2. Effect of the three treatment techniques on the behavior of the different function groups present in wool samples

\begin{tabular}{|c|c|c|c|c|c|c|c|c|c|c|}
\hline \multirow{3}{*}{$\begin{array}{l}\text { Function groups \& } \\
\text { amino acids }\end{array}$} & \multirow{3}{*}{ Blank } & \multicolumn{9}{|c|}{ Different Treatment Techniques } \\
\hline & & \multirow{2}{*}{$\begin{array}{l}\mathrm{UV} \backslash \mathrm{Ozone}(20 \\
\min ) \\
\text { (Treatment } \mathrm{I})\end{array}$} & \multicolumn{4}{|c|}{$\begin{array}{l}\text { Chitosan conc. } \\
\text { (Treatment II) }\end{array}$} & \multicolumn{4}{|c|}{$\begin{array}{c}\text { Combined UV and chitosan } \\
\text { (Treatment III) }\end{array}$} \\
\hline & & & $0.5 \%$ & $1 \%$ & $1.5 \%$ & $2 \%$ & $0.5 \%$ & $1 \%$ & $1.5 \%$ & $2 \%$ \\
\hline $\begin{array}{l}3566 \mathrm{~cm}^{-1} \mathrm{O}-\mathrm{H} \text { Assym. } \\
\text { stretch }\end{array}$ & 8.24 & 9.86 & 9.00 & 8.44 & 8.08 & 8.04 & 9.69 & 10.73 & 11.53 & 11.10 \\
\hline $\begin{array}{l}3275 \mathrm{~cm}^{-} \mathrm{N}-\mathrm{H} \text { stretch } \\
\text { (Serine) }\end{array}$ & 20.1 & 21.3 & 20.5 & 21.9 & 23.0 & 23.7 & 24.8 & 25.9 & 25.7 & 26.8 \\
\hline $2925 \mathrm{~cm}^{-1} \mathrm{C}-\mathrm{H}$ stretch & 13.2 & 18.2 & 14.4 & 15.2 & 16.6 & 17.0 & 17.0 & 18.8 & 19.9 & 20.7 \\
\hline $\begin{array}{l}1645 \mathrm{~cm}^{-} \mathrm{C}=\mathrm{O} \text { stretch } \\
(\text { Aspartic })\end{array}$ & 80.0 & 84.0 & 84.2 & 84.8 & 84.8 & 84.9 & 81.6 & 81.7 & 82.4 & 83.2 \\
\hline $\begin{array}{l}1610 \mathrm{~cm}^{-1} \mathrm{~N}-\mathrm{H} \text { bending } \\
\text { (Lysine) }\end{array}$ & 75.1 & 76.8 & 82.9 & 83.4 & 84.8 & 88.3 & 75.15 & 76.19 & 74.8 & 77.9 \\
\hline $\begin{array}{l}1520 \mathrm{~cm}^{-1} \\
\mathrm{COO}^{-} \text {carboxylation } \\
\text { (Glutamic) }\end{array}$ & 77.7 & 81.8 & 83.3 & 84.3 & 85.4 & 94.2 & 82.5 & 84.5 & 86.5 & 88.2 \\
\hline $\begin{array}{l}1070 \mathrm{~cm}^{-1} \text { Cystine } \\
\text { monoxide }\end{array}$ & 43.7 & 49.5 & 46.9 & 46.4 & 42.6 & 40.0 & 45.4 & 47.4 & 47.5 & 48.7 \\
\hline
\end{tabular}


Table 3. Effect of the three treatment techniques on the behavior of the different function groups present in silk samples

\begin{tabular}{|c|c|c|c|c|c|c|c|c|c|c|}
\hline \multirow[t]{3}{*}{ Function group } & \multirow[t]{3}{*}{ Blank } & \multicolumn{9}{|c|}{ Different Treatment Techniques } \\
\hline & & \multirow[t]{2}{*}{$\begin{array}{l}\mathrm{UV} \backslash \text { Ozone }(20 \\
\min ) \\
\text { (Treatment I) }\end{array}$} & \multicolumn{4}{|c|}{$\begin{array}{l}\text { Chitosan conc. } \\
\text { (Treatment II) }\end{array}$} & \multicolumn{4}{|c|}{$\begin{array}{c}\text { Combined UV and } \\
\text { chitosan } \\
\text { (Treatment III) }\end{array}$} \\
\hline & & & $0.5 \%$ & $1 \%$ & $1.5 \%$ & $2 \%$ & $0.5 \%$ & $1 \%$ & $1.5 \%$ & $2 \%$ \\
\hline $\begin{array}{l}3280 \mathrm{~cm}^{-1} \text { N-H stretch } \\
(\text { Serine })\end{array}$ & 31.3 & 33.4 & 34.5 & 33.4 & 33.8 & 34.7 & 34.8 & 33.2 & 32.4 & 30.6 \\
\hline $\begin{array}{l}2920 \mathrm{~cm}^{-1} \mathrm{C}-\mathrm{H} \\
\text { stretch }\end{array}$ & 14.6 & 15.7 & 16.8 & 17.0 & 18.2 & 19.7 & 19.3 & 16.0 & 15.5 & 15.2 \\
\hline $\begin{array}{l}1619 \mathrm{~cm}^{-1} \mathrm{~N}-\mathrm{H} \text { bending } \\
(\text { Lysine })\end{array}$ & 97.1 & 98.9 & 100.02 & 99.7 & 92.4 & 81.9 & 99.8 & 97.2 & 97.6 & 95.7 \\
\hline $\begin{array}{l}1515 \mathrm{~cm}^{-1} \mathrm{C}=\mathrm{O} \text { assym. } \\
\text { Stretch (Glutamic) }\end{array}$ & 81.1 & 84.2 & 81.6 & 82.5 & 83.4 & 84.4 & 85.9 & 84.0 & 82.1 & 79.9 \\
\hline $\begin{array}{l}1443 \mathrm{~cm}^{-1} \mathrm{C}-\mathrm{C} \text { stretch } \\
\text { in ring (Tyrosine) }\end{array}$ & 49.9 & 55.0 & 51.9 & 53.0 & 53.4 & 54.6 & 63.5 & 58.9 & 53.1 & 49.0 \\
\hline $1231 \mathrm{~cm}^{-1} \mathrm{C}-\mathrm{N}$ stretch & 50.4 & 54.7 & 51.6 & 52.7 & 53.2 & 56.6 & 59.0 & 56.1 & 57.0 & 55.7 \\
\hline
\end{tabular}

Table 4. The change in whiteness (W) and yellowness $(\mathrm{Y})$ parameters of wool and silk fabrics modified with the three different techniques

\begin{tabular}{|c|c|c|c|c|c|c|c|c|c|c|}
\hline \multirow[t]{2}{*}{ Fabric } & \multicolumn{2}{|c|}{ Blank } & \multicolumn{2}{|c|}{$\begin{array}{c}\mathrm{UV} \backslash \text { Ozone }(20 \mathrm{~min}) \\
\text { (Treatment I) }\end{array}$} & \multicolumn{3}{|c|}{$\begin{array}{l}\text { Chitosan conc. } \\
\text { (Treatment II) }\end{array}$} & \multicolumn{3}{|c|}{$\begin{array}{c}\text { Combined UV and chitosan } \\
\text { (Treatment III) }\end{array}$} \\
\hline & W & $\mathrm{Y}$ & W & Y & Conc. & W & Y & Conc. & W & Y \\
\hline \multirow[t]{4}{*}{ wool } & \multirow[t]{4}{*}{10.53} & \multirow[t]{4}{*}{18.52} & \multirow[t]{4}{*}{6.87} & \multirow[t]{4}{*}{20.52} & $0.5 \%$ & 11.34 & 17.98 & $0.5 \%$ & 4.32 & 21.3 \\
\hline & & & & & $1 \%$ & 13.29 & 17.25 & $1 \%$ & -2.81 & 22.09 \\
\hline & & & & & $1.5 \%$ & 13.84 & 16.19 & $1.5 \%$ & -4.89 & 22.41 \\
\hline & & & & & $2 \%$ & 14.23 & 15.22 & $2 \%$ & -7.25 & 22.65 \\
\hline \multirow[t]{4}{*}{ silk } & \multirow[t]{4}{*}{25.48} & \multirow[t]{4}{*}{17.06} & \multirow[t]{4}{*}{12.36} & \multirow[t]{4}{*}{22.35} & $0.5 \%$ & 20.78 & 19.18 & $0.5 \%$ & -7.26 & 27.90 \\
\hline & & & & & $1 \%$ & 16.25 & 20.35 & $1 \%$ & 1.56 & 24.27 \\
\hline & & & & & $1.5 \%$ & 1033 & 27.15 & $1.5 \%$ & 7.34 & 21.88 \\
\hline & & & & & $2 \%$ & -17.62 & 33.95 & $2 \%$ & 15.12 & 20.14 \\
\hline
\end{tabular}


Table 5. Wettability (sec.) of wool and silk fabrics modified with either chitosan or uvlozone or both combined together

\begin{tabular}{|c|c|c|c|c|c|c|}
\hline \multirow[t]{2}{*}{ Fabric } & $\begin{array}{c}\text { Blank } \\
\text { (Wetting time sec.) }\end{array}$ & $\begin{array}{l}\text { UV } \backslash \text { Ozone }(20 \mathrm{~min}) \\
\text { (Wetting time sec.) }\end{array}$ & \multicolumn{2}{|c|}{$\begin{array}{l}\text { Chitosan conc. } \\
\text { (Treatment II) }\end{array}$} & \multicolumn{2}{|c|}{$\begin{array}{l}\text { Combined UV and chitosan } \\
\text { (Treatment III) }\end{array}$} \\
\hline & \multirow{5}{*}{1238} & \multirow{5}{*}{705} & Conc. & Wetting time sec. & Conc. & Wetting time sec. \\
\hline \multirow{4}{*}{$\begin{array}{l}\overrightarrow{8} \\
\overline{3}\end{array}$} & & & $0.5 \%$ & 707 & $0.5 \%$ & 790 \\
\hline & & & $1 \%$ & 431 & $1 \%$ & 555 \\
\hline & & & $1.5 \%$ & 307 & $1.5 \%$ & 120 \\
\hline & & & $2 \%$ & 110 & $2 \%$ & 101 \\
\hline \multirow{4}{*}{ 㮍 } & \multirow{4}{*}{720} & \multirow{4}{*}{360} & $0.5 \%$ & 300 & $0.5 \%$ & 330 \\
\hline & & & $1 \%$ & 220 & $1 \%$ & 280 \\
\hline & & & $1.5 \%$ & 190 & $1.5 \%$ & 190 \\
\hline & & & $2 \%$ & 135 & $2 \%$ & 110 \\
\hline
\end{tabular}

Table 6. Mechanical properties of wool and silk fabrics modified with either uvlozone or chitosan or both together

\begin{tabular}{|c|c|c|c|c|c|c|c|c|c|c|c|}
\hline \multirow[t]{2}{*}{ Fabric } & \multirow{2}{*}{$\begin{array}{l}\text { Mechanical } \\
\text { properties }\end{array}$} & \multirow[t]{2}{*}{ Blank } & \multirow{2}{*}{$\begin{array}{c}\mathrm{UV \backslash \text {Ozone }}(20 \\
\text { min) } \\
\text { (Treatment I) }\end{array}$} & \multicolumn{4}{|c|}{$\begin{array}{l}\text { Chitosan conc. } \\
\text { (Treatment II) }\end{array}$} & \multicolumn{4}{|c|}{$\begin{array}{l}\text { Combined UV and chitosan } \\
\text { (Treatment III) }\end{array}$} \\
\hline & & & & $0.5 \%$ & $1 \%$ & $1.5 \%$ & $2 \%$ & $0.5 \%$ & $1 \%$ & $1.5 \%$ & $2 \%$ \\
\hline \multirow[t]{3}{*}{ Wool } & $\begin{array}{l}\text { Tensile } \\
\text { strength }\end{array}$ & 7.15 & 7.89 & 7.69 & 7.99 & 7.45 & 7.49 & 8.08 & 8.66 & 8.63 & 8.74 \\
\hline & \%elongation & 13.03 & 11.23 & 13.7 & 12.56 & 11.04 & 10.88 & 11.91 & 12.82 & 13.11 & 14.90 \\
\hline & E- Modulus & 32.04 & 34.91 & 32.55 & 33.67 & 36.82 & 38.20 & 33.70 & 35.31 & 34.9 & 36.50 \\
\hline \multirow[t]{3}{*}{ Silk } & $\begin{array}{l}\text { Tensile } \\
\text { strength }\end{array}$ & 6.28 & 1.18 & 5.80 & 6.43 & 7.36 & 8.75 & 6.82 & 7.60 & 8.07 & 9.93 \\
\hline & \%elongation & 9.37 & 4.23 & 9.30 & 8.74 & 7.21 & 7.04 & 6.14 & 5.97 & 5.44 & 5.02 \\
\hline & E- Modulus & 15.39 & 15.77 & 10.71 & 10.54 & 10.02 & 9.93 & 11.25 & 10.63 & 10.28 & 10.00 \\
\hline
\end{tabular}

Table 7. Effect of the three different techniques on dyeing properties of wool and silk samples dyed with reactive dye

\begin{tabular}{|c|c|c|c|c|c|c|c|c|c|c|c|c|c|c|}
\hline \multirow{2}{*}{ 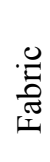 } & \multicolumn{3}{|c|}{ Blank } & \multicolumn{3}{|c|}{$\begin{array}{l}\mathrm{UV} \backslash \text { Ozone }(20 \mathrm{~min}) \\
\text { (Treatment I) }\end{array}$} & \multicolumn{4}{|c|}{$\begin{array}{l}\text { Chitosan conc. } \\
\text { (Treatment II) }\end{array}$} & \multicolumn{4}{|c|}{$\begin{array}{l}\text { Combined UV and chitosan } \\
\text { (Treatment III) }\end{array}$} \\
\hline & $\mathrm{K} \backslash \mathrm{S}$ & $\Delta \mathrm{E}$ & L.F. & $\mathrm{K} \backslash \mathrm{S}$ & $\Delta \mathrm{E}$ & L.F. & Conc. & $\mathrm{K} \backslash \mathrm{S}$ & $\Delta \mathrm{E}$ & L.F. & Conc. & $\mathrm{K} \backslash \mathrm{S}$ & $\Delta \mathrm{E}$ & L.F. \\
\hline \multirow{4}{*}{$\begin{array}{l}\overline{8} \\
8 \\
3\end{array}$} & \multirow{4}{*}{2.45} & \multirow{4}{*}{2.12} & \multirow{4}{*}{5} & \multirow{4}{*}{4.84} & \multirow{4}{*}{1.05} & \multirow{4}{*}{$5 / 6$} & $0.5 \%$ & 4.87 & 2.31 & $5 / 6$ & $0.5 \%$ & 8.45 & 1.83 & $5 / 6$ \\
\hline & & & & & & & $1 \%$ & 4.55 & 1.93 & $5 / 6$ & $1 \%$ & 9.06 & 1.50 & $5 / 6$ \\
\hline & & & & & & & $1.5 \%$ & 5.95 & 1.30 & 6 & $1.5 \%$ & 9.06 & 1.08 & 6 \\
\hline & & & & & & & $2 \%$ & 6.25 & 0.87 & 6 & $2 \%$ & 10.95 & 1.03 & $6 / 7$ \\
\hline \multirow{4}{*}{ 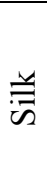 } & \multirow{4}{*}{1.84} & \multirow{4}{*}{3.76} & \multirow{4}{*}{4} & \multirow{4}{*}{3.12} & \multirow{4}{*}{2.51} & \multirow{4}{*}{$4 / 5$} & $0.5 \%$ & 3.12 & 2.20 & 5 & $0.5 \%$ & 3.67 & 2.42 & 5 \\
\hline & & & & & & & $1 \%$ & 3.64 & 1.64 & $5 / 6$ & $1 \%$ & 3.73 & 1.60 & 5 \\
\hline & & & & & & & $1.5 \%$ & 3.89 & 1.05 & $5 / 6$ & $1.5 \%$ & 4.02 & 1.00 & $5 / 6$ \\
\hline & & & & & & & $2 \%$ & 4.19 & 0.98 & 6 & $2 \%$ & 4.87 & 0.71 & $5 / 6$ \\
\hline
\end{tabular}


Table 8. Effect of the three different techniques on dyeing properties of wool and silk samples dyed with direct dye

\begin{tabular}{|c|c|c|c|c|c|c|c|c|c|c|c|c|c|c|}
\hline \multirow[t]{2}{*}{$\begin{array}{l}.00 \\
\text { 产 }\end{array}$} & \multicolumn{3}{|c|}{ Blank } & \multicolumn{3}{|c|}{$\begin{array}{l}\text { UV } \backslash \text { Ozone }(20 \mathrm{~min}) \\
\text { (Treatment I) }\end{array}$} & \multicolumn{4}{|c|}{$\begin{array}{l}\text { Chitosan conc. } \\
\text { (Treatment II) }\end{array}$} & \multicolumn{4}{|c|}{$\begin{array}{c}\text { Combined UV and chitosan } \\
\text { (Treatment III) }\end{array}$} \\
\hline & $\mathrm{K} \backslash \mathrm{S}$ & $\Delta \mathrm{E}$ & L.F. & $\mathrm{K} \backslash \mathrm{S}$ & $\Delta \mathrm{E}$ & L.F. & Conc. & $\mathrm{K} \backslash \mathrm{S}$ & $\Delta \mathrm{E}$ & L.F. & Conc. & $\mathrm{K} \backslash \mathrm{S}$ & $\Delta \mathrm{E}$ & L.F. \\
\hline \multirow{4}{*}{$\begin{array}{l}\overline{8} \\
\overline{3}\end{array}$} & \multirow{4}{*}{2.81} & \multirow{4}{*}{3.13} & \multirow{4}{*}{$4 / 5$} & \multirow{4}{*}{3.10} & \multirow{4}{*}{1.08} & \multirow{4}{*}{5} & $0.5 \%$ & 3.53 & 2.35 & $5 / 6$ & $0.5 \%$ & 4.59 & 1.09 & $5 / 6$ \\
\hline & & & & & & & $1 \%$ & 4.16 & 1.32 & $5 / 6$ & $1 \%$ & 4.74 & 1.01 & 6 \\
\hline & & & & & & & $1.5 \%$ & 5.63 & 1.14 & 6 & $1.5 \%$ & 5.01 & 0.80 & $6 / 7$ \\
\hline & & & & & & & $2 \%$ & 6.01 & 1.01 & 6 & $2 \%$ & 6.72 & 0.60 & $6 / 7$ \\
\hline \multirow{4}{*}{ 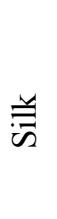 } & \multirow{4}{*}{1.79} & \multirow{4}{*}{3.01} & \multirow{4}{*}{$4 / 5$} & \multirow{4}{*}{2.06} & \multirow{4}{*}{2.84} & \multirow{4}{*}{5} & $0.5 \%$ & 3.20 & 3.09 & $5 / 6$ & $0.5 \%$ & 3.55 & 3.98 & $5 / 6$ \\
\hline & & & & & & & $1 \%$ & 4.24 & 2.39 & $5 / 6$ & $1 \%$ & 4.27 & 2.88 & $5 / 6$ \\
\hline & & & & & & & $1.5 \%$ & 5.06 & 2.06 & 6 & $1.5 \%$ & 5.99 & 2.61 & 6 \\
\hline & & & & & & & $2 \%$ & 5.91 & 1.22 & 6 & $2 \%$ & 6.45 & 2.11 & 6 \\
\hline
\end{tabular}
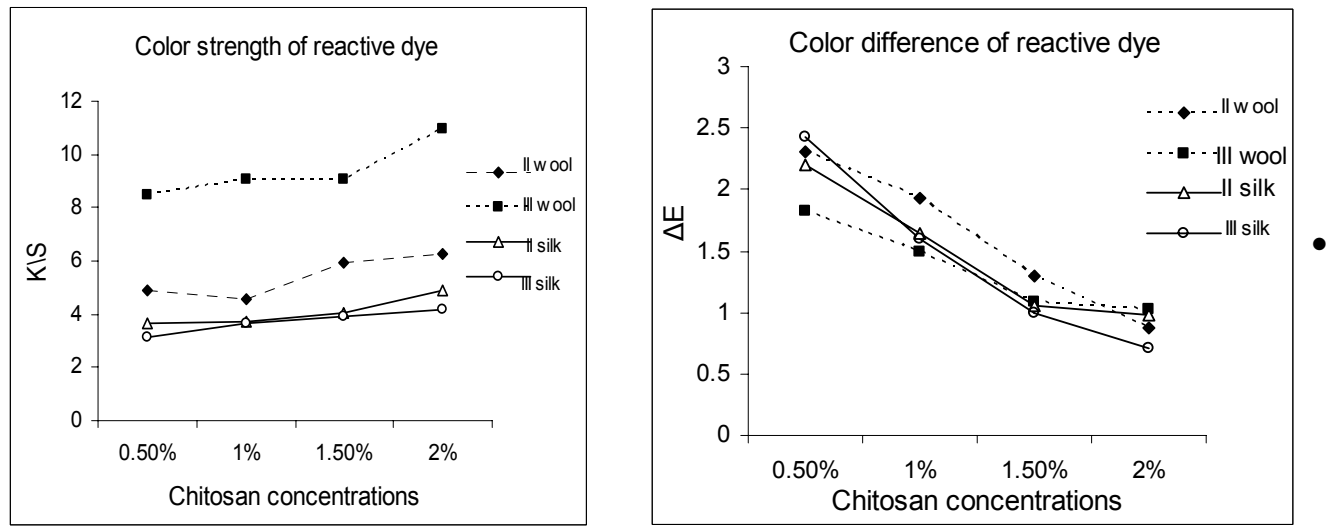

Figure 1. Dyeing properties of reactive dye applied on treated wool and silk samples
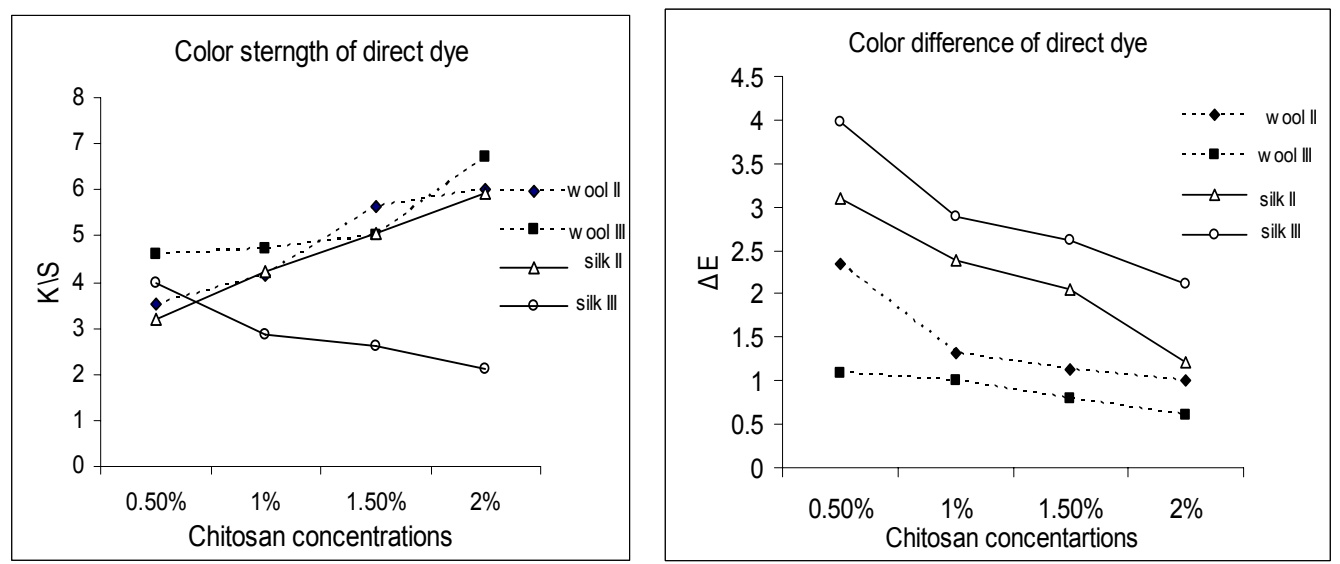

Figure 2. Dyeing properties of direct dye applied on treated wool and silk samples 